\title{
STATISTICAL ASSESMENT OF WEBOMETRIC RATING INDICATORS OF UKRAINIAN HIGHER EDUCATION INSTITUTIONS
}

\author{
Sergiy Kvitka ${ }^{1}$, Anatolii Rachynskii², Yevgeniy Borodin ${ }^{3}$, Galina Starushenko $^{4}$, Tetiana Lesina ${ }^{5}$, \\ Antonina Kichuk ${ }^{6}$
}

${ }^{I}$ D.Sc., Professor, Dnipropetrovsk Regional Institute for Public Administration of the National Academy for Public Administration under the President of Ukraine. Phone: +0503856415. Email: skvitka1490@ gmail.com

${ }^{2}$ D.Sc., Professor, National Academy for Public Administration under the President of Ukraine. Phone: +0676528651. Email: arachynsky@ukr.net

${ }^{3}$ D.Sc., Professor, Dnipropetrovsk Regional Institute for Public Administration of the National Academy for Public Administration under the President of Ukraine. Phone: +0636578562. Email: e.borodin@vidr.dp.ua

${ }^{4}$ PhD., Associate Professor, Dnipropetrovsk Regional Institute for Public Administration of the National Academy for Public Administration under the President of Ukraine. Phone: +0506587932. Email: gs_gala-star@mail.ru

${ }^{5}$ D.Sc., Professor, Izmail State University of Humanities, Ukraine. Phone: +0678512346. Email: izmayil@ukr.net

${ }^{6}$ PhD., Associate Professor, Izmail State University of Humanities, Ukraine. Phone: +0636578563,

Email: tonya82kichuk@gmail.com

Received 1602 2021; Accepted 01032021

\begin{abstract}
The article is devoted to the statistical analysis of tools, used for the assessment of the international competitiveness of higher education institutions. The analysis has been made based on the Webometric ranking of universities. The aim of the study is to review in details of one of the most important and widely recognized global rankings - Ranking Web of World Universities, determine the place of Ukrainian institutions of higher education in it, identify perspectives for further development and appropriate adjustment of their Web policy.University rankings as a modern information tool for education management have been studied. An analysis of the role of rankings as a mechanism for assessment of universities as educational and research centers has been made. The specifics of Webometric indicators and their impact on the global ranking of the world's leading universities have been analyzed using the professional statistical data processing program STATGRAPHICS Centurion XV.I and the principal components analysis. Based on statistical assessment, the reasons for insufficiently high rating positions of Ukrainian universities in the Webometrics system have been identified. Suggestions on improvement of the presentation indicators of Ukrainian universities in the Internet space, their lifting in the international rating according to Webometric criteria and the qualitative development of domestic scientific and educational school in the context of world trends have been developed. The results of the research can be used by the governing bodies and management of Ukrainian higher education institutions during the creation and adjustment of development strategies, as well as by other specialists who develop, implement and evaluate the state policy of Ukraine in the sphere of higher education.
\end{abstract}

Keywords: university rating, webometric rating, webometrics, web-indicators, ukrainian higher education institutions. JEL Classification: C38, I23, M31.

Copyright (C) 2021 Author(s), published by Vytautas Magnus University. This is an open access article distributed under the terms of the Creative Commons Attribution Non-Commercial 4.0 (CC BY-NC 4.0) license, which permits unrestricted use, distribution, and reproduction in any medium provided the original author and source are credited. The material cannot be used for commercial purposes. 


\section{Introduction}

The key features of the current stage of development of society are the digital transformation that determines the growing level of competition between higher education institutions (HEI). It should be noted that the term "university" is more commonly used in literature. But in Ukraine and many postSoviet countries, the concept of an institution providing higher education includes also academies, institutes, universities, and so on. Therefore, in this study, the term "HEI" integrates also other forms of higher education.

In the context of digitalization of all social processes, the role of the image component of modern HEI, the reputation and qualifications of its teachers and graduates, is growing. On the one hand, modern HEI face the task of providing qualitative education and meeting the needs of more educated and demanding consumers, and on the other hand, they must have a stable financial position as participants in the "educational" market, which will contribute to the development of the national economy (Bantash et al., 2020; Kučaidze, Jurgelevičius, 2020; Yankovyi et al., 2020).

In this regard, there is a growing demand for transparent and objective tools for assessment of education in today's world. Nowadays, the ranking of universities is an integral component of the educational services market (Kodrin, 2020). They are an important factor in market and their impact has become global. Ratings are in demand, easy to use as a tool for assessment of the universities' activity in conditions of intensified competition in the world scientific and educational space.

The relevance of the study of the peculiarities of universities' rating becomes even more significant in light of the new requirements for evaluation of research institutions in Ukraine, which is made according to the Ministry of Education and Science of Ukraine and the papers on expert groups and expert commission, approved by "Some issues on state certification of scientific institutions" order of MES, dated September 17, 2018 for № 1008 (Ministry of Education and Science of Ukraine, 2018).
The aim of the study is to review in details of one of the most important and widely recognized global rankings - Ranking Web of World Universities (Webometrics Ranking of World Universities, 2020), determine the place of Ukrainian HEIs in it, identify perspectives for further development and appropriate adjustment of their Web policy.

Indeed, the rating of Ukrainian HEIs in the Webometrics system is quite low. The best Ukrainian HEI, according to the Webometric Rating in January 2020, - Taras Shevchenko National University of Kyiv - is only 1147 st in the world and 451 th - in Europe (Webometrics Ranking of World Universities, 2020).

Recently, a study was conducted with the aim of building a two-factor model based on the statistical material Webometric Rating of Universities, which analytically describes the state of Ukrainian universities in terms of Webometrics indicators. It made it possible to quantitatively and qualitatively analyze and predict trends in the development of the educational services market in Ukraine (Krush, Zaborovets, Zaborovets, 2010; Kvitka et al., 2019).

The tasks of this article are:

- to make the analysis of the content of the Webometric rating and the methodology for Web-indicators calculating;

- on the basis of statistical material, to study the indicators of the Webometric rating of the best HEIs in the world;

- to make a statistical analysis of the impact of Webometrics indicators on the generalized indicator of the world rating of HEIs;

- to provide an assessment of the position of Ukrainian HEIs in the Webometric rating, to determine characteristics of its indicators;

- to conduct a comparative analysis of the rating of the leading Ukrainian and world HEIs in the Webometrics system;

- to develop recommendations for improvement of the perspectives of presentation in the Internet space, development and appropriate adjustment of the Web-policy of Ukrainian HEIs. 
The information base of the study is the statistical materials on the Webometric rating of the 100 best institutions of the world and the 100 best Ukrainian HEIs according to the latest data (January 2020).

The apparatus of the component analysis and the professional program of processing and analysis of statistical data STATGRAPHICS Centurion XVI have been used as research tools.

\section{Research results and discussion}

\section{HEIs ratings as an information tool for education management}

The process of HEIs ranking is constantly expanding in most countries of the world. Many countries are working hard to compile detailed rankings and to inform the public about their best educational institutions. Growing competition has spurred the development of new information-intensive and easy-to-use tools for assessing the level of HEIs performance. Rating have become such tool (Salmi, Saroyan, 2007); Rauhvargers, 2013).

Ratings consider the assessment of various factors of HEIs performance, which are the subject to summation using the appropriate weight indexes. All ratings differ significantly by the set of assessed factors and the system of weights, but, at the same time, they should be perceived as complementary, not interchangeable information resources.

HEIs ratings are necessary as an information tool for education management. They provide information to potential consumers so that they can make the most grounded and rational choice. The main target groups of ratings include entrants, employers, educational institutions themselves (which need ratings to demonstrate their success in improving their competitive position), representatives of the executive power, employees of international organizations and others.

University rankings became important at the beginning of the XXI century. The first global ranking was ARWU (Academic Ranking of World Universities), which was compiled firstly in China in June 2003 by Higher School of Education (former Institute of Higher Education) of Shanghai Jiao Tong University and then it was updated annually (ShanghaiRanking Consultancy, 2020).

From 2004 to 2009, the British company Quacquarelli Symonds (QS) (2020), which specializes in the analysis of higher education institutions around the world published QS annual rankings of universities together with the Times Higher Education (THE). In 2010, QS - THE split into two independent ratings: QS WUR (Quacquarelli Symonds World University Rankings) continued to use the methodology that existed before, and THE created its own rating in collaboration with the largest news agency Thomson Reuters - THE WUR (Times Higher Education, 2020).

In 2004, the first Ranking Web of World Universities (Webometrics) was suggested by the Cybermetrics Lab (2020) research group, which was the part of Madrid's largest public research center - the Spanish National Research Council (Spanish: CSIC) (2020). The main characteristic of the Webometric Rating, which distinguishes it from others, is the wide coverage of HEIs of the world: in January 2019 more than 28,000 universities from all over the world were assessed (Hedclub, 2019), of which 323 were Ukrainian (Euroosvita, 019); in January 2020 - more than 30 thousand, of which 315 were Ukrainian (Webometrics Ranking of World Universities, 2020).

Copyright (C) 2021 Author(s), published by Vytautas Magnus University. This is an open access article distributed under the terms of the Creative Commons Attribution Non-Commercial 4.0 (CC BY-NC 4.0) license, which permits unrestricted use, distribution, and reproduction in any medium provided the original author and source are credited. The material cannot be used for commercial purposes. 
Analysis of the content of Webometric rating and methodology for calculating Web-indicators

Webometric researchers based on quantitative analysis of Internet content are a relatively new area of scientific research. The term "Webometrics" was introduced firstly by Tomas Almind and Peter Ingwersen in 1997 to name the process of studying all information on the World Wide Web (WWW), using infometry and other quantitative indicators (Almind, Ingwersen, 1997).). In the later work of Ingversen (2006) this concept was clarified and defined as the study of quantitative aspects of the design and use of information resources, structures and technologies in the network. This concept is based on bibliometric and infometric approaches.

Today, the leading position in conducting Webometric researchers is occupied by the Cybernetic Laboratory of the Center for Scientific Information and Documentation of the Spanish National Research Council (2020). This center implemented the project "World Webometric Rating of Universities", which is one of the most famous and large HEIs rankings. Since 2004, every six months (in the first weeks of January and July), the Cybernetics Laboratory conducts independent data collection to obtain comprehensive information on the presence of universities as research centers on the Internet and publishes an updated ranking in late January - early February and late July - early August.

The primary goal of the project was not so much to create a ranking of educational institutions, but to stimulate Web-activity of university publications. The main task of the rating is to motivate research and educational institutions to post information about their advanced educational technologies and researchers in the public domain (Hazelkorn, 2015). Webometric rating allows assessing the teaching and research achievements of universities by comparing their sites.

Webometric rating indicators are based not only on the number of visits and page design of Websites, but on the completeness of the presentation of HEIs in the network. According to the authors of the rating, Webindicators - in contrast to academic rankings, which reflect certain aspects of educational activities and research results of the university - assess indirectly all aspects of HEIs performance: network activity, online presence of teachers and students, educational work, availability of educational and methodical materials, scientific activity, social status, extracurricular life, cultural events, sports achievements, etc. (Kunosić, Čeke, Zerem, 2019).

Universities carry out a variety of pedagogical, scientific, cultural, sports, socially oriented activities and this is reflected on their Websites. That is why - unlike other university rankings, in which the values of the indicators, which are taken into account, do not change for a long time - in the Webometric rating there are constant changes in Webindicators. Their improvement and adjustment of weights is aimed at the improvement of the objectivity of rating points.

In January 2020 the following Webindicators were used to build the Webometric rating. A brief description and weighting of each indicator is presented in table. 2.1. 


\section{Sciendo}

Management Theory and Studies for Rural Business and Infrastructure Development eISSN 2345-0355. 2021. Vol. 43. No. 2: 177-194

Article DOI: https://doi.org/10.15544/mts.2021.15

Table 1. Methodology for calculating Web-indicators of Webometric rating in January 2020 (Webometrics Ranking of World Universities, 2020)

\begin{tabular}{|l|l|l|l|c|}
\hline \multicolumn{1}{|c|}{ Indicator } & \multicolumn{1}{|c|}{ Content } & \multicolumn{1}{|c|}{ Description } & Source & Weight \\
\hline PRESENCE & $\begin{array}{l}\text { Collective } \\
\text { public } \\
\text { knowledge }\end{array}$ & $\begin{array}{l}\text { Amount (number of pages) of the main Web- } \\
\text { domain of the institution and all its } \\
\text { subdomains }\end{array}$ & Google & $5 \%$ \\
\hline VISIBILITY & $\begin{array}{l}\text { Impact of the } \\
\text { Web-content }\end{array}$ & $\begin{array}{l}\text { Number of external networks (subnets) } \\
\text { connected to the University's web pages (the } \\
\text { average value is selected after normalization) }\end{array}$ & $\begin{array}{l}\text { Ahrefs } \\
\text { Majestic }\end{array}$ & $50 \%$ \\
\hline $\begin{array}{l}\text { TRANSPARENCY } \\
\text { (or OPENNESS) }\end{array}$ & $\begin{array}{l}\text { Top-cited } \\
\text { researchers }\end{array}$ & $\begin{array}{l}\text { Number of citations from the top 110 authors } \\
\text { (excluding the top 10 authors to improve } \\
\text { representativeness by removing emissions) }\end{array}$ & $\begin{array}{l}\text { Google } \\
\text { Scholar } \\
\text { Profiles }\end{array}$ & $10 \%$ \\
\hline $\begin{array}{l}\text { EXCELLENCE } \\
\text { (or SCHOLAR) }\end{array}$ & $\begin{array}{l}\text { Top-quoted } \\
\text { scientific papers }\end{array}$ & $\begin{array}{l}\text { Number of papers written by university } \\
\text { scientists, which are included in the top 10\% } \\
\text { of the most cited in 26 disciplines. Data are } \\
\text { taken for a five-year period: } 2013 \text { - 2017 }\end{array}$ & Scimago & $35 \%$ \\
\hline
\end{tabular}

The interest of researchers in Webometric ranking is growing due to, on the one hand, the global coverage of universities around the world, on the other hand - a significant frequency of updating ranking data (twice a year), which allows HEIs not only to analyze constantly their advantages and disadvantages and to regulate their Web-policy on this basis, but also to assess the competitiveness of their educational and scientific activities and to intensify efforts to its improvement (Koval, Polyezhayev, Bezkhlibna, 2018).

\section{Statistical study of the world's leading universities Webometric ranking}

A sample of ratings of the 100 best world universities and their corresponding indicators of Web-indexes have been selected to study the indicators of the Webometric rating of world universities. The study has been made on the basis of statistical material from Webometrics in January 2020 (Webometrics Ranking of World Universities, 2020). A fragment of this study is shown in Fig. 1.

Copyright (C) 2021 Author(s), published by Vytautas Magnus University. This is an open access article distributed under the terms of the Creative Commons Attribution Non-Commercial 4.0 (CC BY-NC 4.0) license, which permits unrestricted use, distribution, and reproduction in any medium provided the original author and source are credited. The material cannot be used for commercial purposes. 


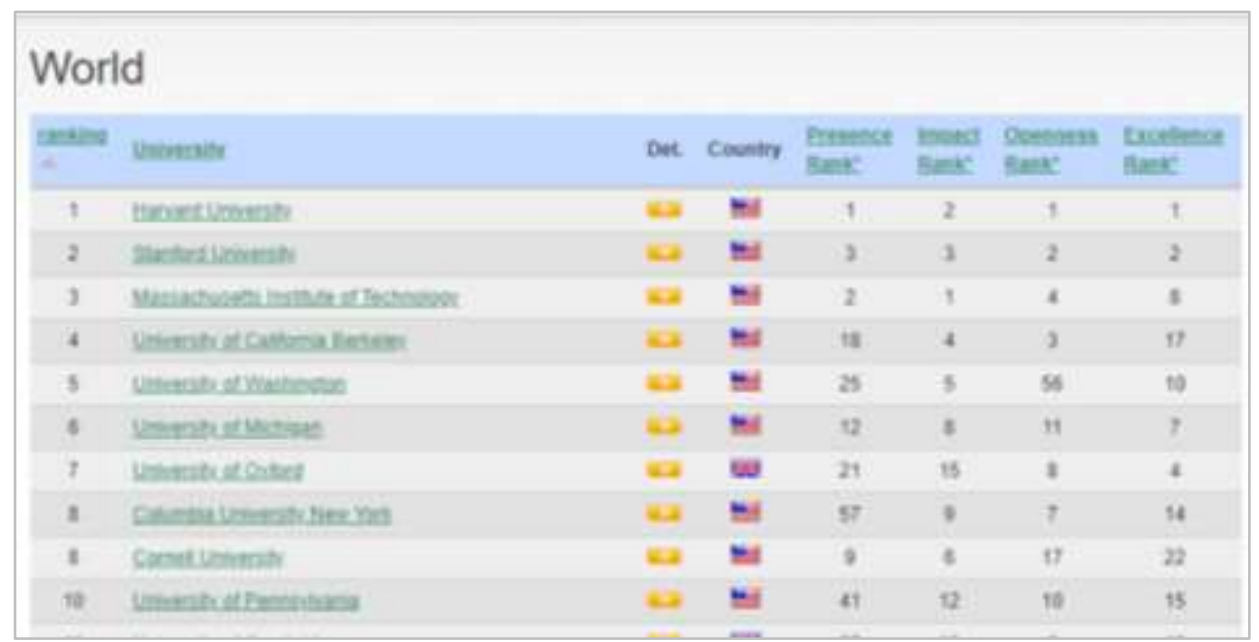

Figure 1. Rankings of the 10 best world universities by Webometrics in January 2020

(Webometrics Ranking of World Universities, 2020)

The analysis of the indicators of the Webometric rating of the world's universities has been made on the basis of the principal components analysis (Erina, 2001; Johnson, Wichern, 2007). The main task of the method is to identify hidden (latent) but objectively existing root causes, which explain the correlations between traits, have a real meaning (determined by the nature of the factors under consideration), can be numerically measured and meaningfully interpreted.

The choice of the method of the principal components analysis is grounded also by the following important advantages in the context of this study:

- a description of the studied system, which is much smaller than the initial number of factors, without the loss of relevant information; moreover, the identified factors the principal components - may contain even more generalized information about the object under study than the initial ones;

- the possibility to build generalized statistical indicators of the studied object. In addition, the classification by generalized statistical indicators is more adequate and objective than the classification of the same factors by base features;

- construction of regression models by principal components. In multidimensional statistical analysis, the initial factors are often multicollinear (correlated with each other) and this complicates the building and interpretation of regression models. At the same time, the main components, retaining all information about the studied object, are not correlated by definition and building;

- when reducing the number of initial factors to 1 - 3 principal components, it becomes possible to make the visual illustration of the results of the study.

The principal components analysis should be used in the case when the factor variables $x_{i}(i=1,2, \ldots, m)$ are included in the model and are multicollinear.

For a studied sample of ratings of the 100 best world universities, we introduce the meanings:

$z_{W}$ - performance variable: World ranking of universities / World Rank;

$x_{i}(i=1,2,3,4)$ - factor variables, presented grounding on their weight (Table 1 ), namely (Fig. 1): $x_{1}$ : (Presence) $\cdot 0,05 ; x_{2}$ : (Impact) $\cdot 0,5 ; \quad x_{3}$ : (Openness) $\cdot 0,1 ; x_{4}$ : (Excellence) $\cdot 0,35$; the index $« \mathrm{~W} »$ means that the specified variable describes the world ranking of universities.

\section{Calculation for the initial factor variables $X=\left\{x_{i}, i=1,2, \ldots, m\right\}$ of the correlation matrix}

For the layout of the correlation matrix, calculated from the list of the MultipleVariable Analyzes tool in the STATGRAPHICS Centurion XV.I a pair of factor variables $x_{1}$ and $x_{2} ; x_{1}$ and $x_{4} ; x_{2}$ 


\title{
Sciendo
}

\author{
Management Theory and Studies for Rural Business and Infrastructure Development \\ eISSN 2345-0355. 2021. Vol. 43. No. 2: 177-194 \\ Article DOI: https://doi.org/10.15544/mts.2021.15
}

and $x_{3} ; x_{3}$ and $x_{4}$ have values $P$ below 0,05 .

This indicates the presence of multicollinearity.

Therefore, in accordance with the principal components analysis, the principal components should be separated and the factor loads should be calculated.

\section{Separation of principal components} $Y=\left\{y_{j}, i=1,2, \ldots, n\right\}$ of factor variables

The main components are those, for which eigenvalues $\lambda_{j}$ satisfy the condition $\lambda_{j}>1(j=1,2, \ldots, n)$ by the Kaiser criterion (Erina, 2001).). Main components for the selected sample of values have been determined using the Principal Components

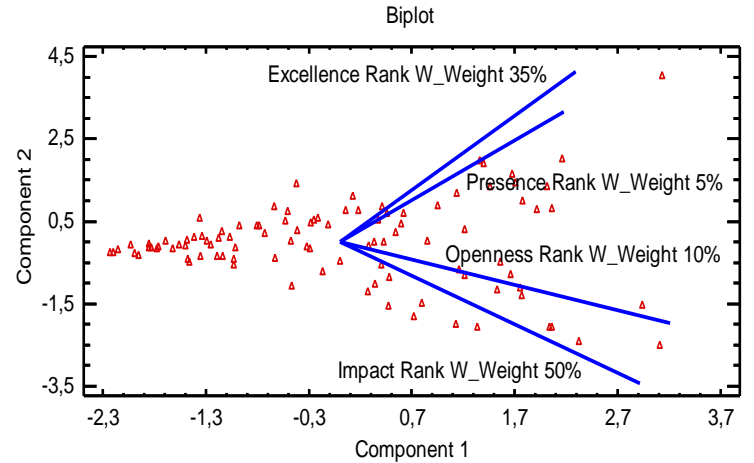

Figure 2. Biplot-chart: graphs of Webindicators' component weights and statistics in the principal components' coordinate axes

According to the calculated data, equations of the principal components $y_{I W}$, $y_{2 W}$ for a sample set of Web-indicators of the top 100 world universities according to the data in January 2020 have been recorded in the form:

$y_{I W}=0,405144 x_{1}^{*}+0,543352 x_{2}^{*}+0,598257 x_{3}^{*}+0,427452 x_{4}^{*}$;

(3.1)
Analysis tool of the STATGRAPHICS program (Kvitka, Starushenko, 2021).

In the studied case, 2 principal components have been obtained from 4 initial factors, as they have eigenvalues that exceed 1 :

$$
\lambda_{1}=1,88074 ; \lambda_{2}=1,04628 .
$$

The contribution of the first principal component to the total variance of the studied set is $47,019 \%$, the second one $-26,157 \%$. Therefore, the main components together explain $73,175 \%$ of the variability of the original data, which indicates a rather high degree of factorization.

In the Biplot graph (Fig. 2) the spots show statistical data in the principal components' coordinate axes; solid lines show the weights of Web-indicators in the principal components.

Plot of Factor Loadings

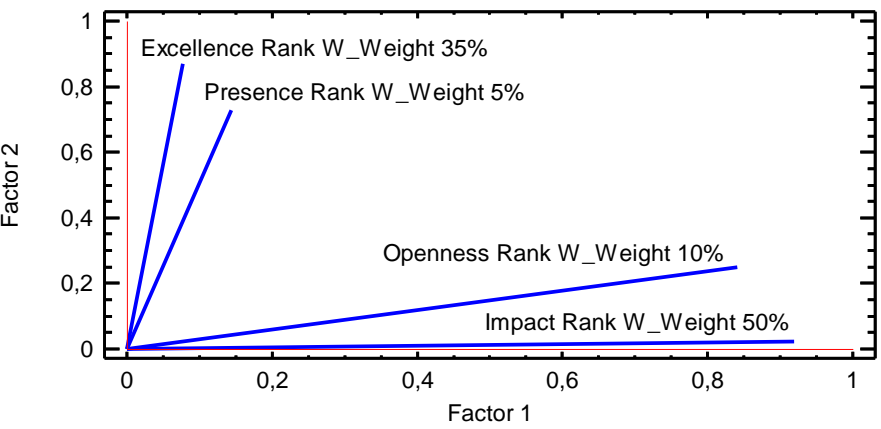

Figure 3. Graph of factor loads after rotation procedure $y_{2 W}=0,482876 x_{1}^{*}-0,525432 x_{2}^{*}-0,301573 x_{3}^{*}+0,632301 x_{4}^{*}$,

where $x_{i}^{*}(i=1,2,3,4) \quad$ - standardized values of variables $x_{i}$ :

$$
x_{i}^{*}=\frac{x_{i}-\overline{x_{i}}}{\sigma_{i}} \text {; }
$$

Copyright (C 2021 Author(s), published by Vytautas Magnus University. This is an open access article distributed under the terms of the Creative Commons Attribution Non-Commercial 4.0 (CC BY-NC 4.0) license, which permits unrestricted use, distribution, and reproduction in any medium provided the original author and source are credited. The material cannot be used for commercial purposes. 
$\bar{x}_{i}$ - average values of factors $x_{i}(i=1,2,3,4) ; \sigma_{i}$ - their standard deviations.

\section{Calculation of factor loads and identification of principal components}

The correlation between the primary features $X=\left\{x_{i}, i=1,2, \ldots, m\right\}$ and the principal components $\quad Y=\left\{y_{j}, j=1,2, \ldots, n\right\} \quad$ - the calculation of which is the purpose of the factor analysis can be determined by the method presented in matrix form in Johnson and Wichern (2007). The calculation of factor loads was performed using the Factor Analysis tool.

To simplify the identification of components, it is advisable to transform the resulting factor structure using the rotation procedure. In STATGRAPHICS this procedure has been made using the Factor Analysis tool. According to the calculated data (Kvitka, Starushenko, 2021) factor loads, after the implementation of the selected procedure of rotation Varimax are written by analytical equations in the form:

$l_{1}^{\prime}=0,144601 x_{1}^{*}+O, 9185 x_{2}^{*}+0,840242 x_{3}^{*}+0,0766876 x_{4}^{*} ;$

$l_{2}^{\prime}=0,729217 x_{1}^{*}+0,0215882 x_{2}^{*}+0,249574 x_{3}^{*}+0,86952 x_{4}^{*}$.

The graph of factor loads after the rotation procedure has been shown in Fig. 3.3.

Thus, based on the results of the main components and factor loads' calculation for a sample set of Web-indicators of the top 100 world universities according to data in January 2020 and taking into account the current methodology for compiling the Webometrix rating, we obtain:

1) The first principal component $y_{I W}$ is strongly related to the Webometric indicators Impact and Openness and can be identified as "Openness and impact of Web content". This component is the most important as it makes the largest contribution to the total variance of the set of factor features.

2) The second principal component $y_{2 W}$ is related mainly to the Web indicators
Presence and Excellence and can be interpreted as "Volume and quality of collective social knowledge".

Separation and identification of principal components makes it possible to build a regression model for principal components correctly. This is a model in which all information about the object under study is saved and the factor features are not correlated.

Statistical analysis of the impact of Webometrics indicators on the generalized indicator of the world university ranking

To analyze the impact of Webometric indicators on the generalized world university ranking, a two-factor regression model of the dependence of the performance trait $z_{W}$ World Rank of Universities / World Rank on $y_{I W}, y_{2 W}$ - the principal components of Webindicators of the top 100 world universities according to January 2020 have been built. It has been reflected by (3.1) - (3.3) formulas.

Using the Multiple Regression tool of the STATGRAPHICS program, we obtain that the required regression equation is described by a linear relation:

$$
z_{W}\left(y_{I W}, y_{2 W}\right)=50,44+20,0701 y_{I W}+0,42089 y_{2 W} \text {. }
$$

The regression equation (4.1) is the best in comparison with the alternative models, offered by the Multiple Regression Options function of the STATGRAPHICS program, as it has the highest coefficient of determination ( $R$-squared) $R^{2}=90,1031$. The value of the statistics $R^{2}$ indicates a close correlation between factor and performance traits and indicates that the model explains $90,1031 \%$ of the variation in the performance trait.

It should be noted that, if necessary, the regression equation (4.1) - the equation of an adequate correlation model with uncorrelated factors - can be presented taking into account the relations (3.1) - (3.3) as a function of the original variables and can be analyzed under each of them. In this case, the equation is written in the form: 


\section{Sciendo}

Management Theory and Studies for Rural Business and Infrastructure Development

eISSN 2345-0355. 2021. Vol. 43. No. 2: 177-194

Article DOI: https://doi.org/10.15544/mts.2021.15

$z_{W}\left(x_{1}, x_{2}, x_{3}, x_{4}\right)=4,81385+1,12787 x_{1}+0,370844 x_{2}+2,16129 x_{3}+0,405247 x_{4}$

The dependence of the regression function $z_{W}$ on factors $x_{i}(i=1,2,3,4)(4.2)$, can be visually illustrated, for example, by plotting functions:

$$
\begin{aligned}
& z_{W}\left(x_{1}, x_{2}\right)=z_{W}\left(x_{1}, x_{2}, \overline{x_{3}}, \overline{x_{4}}\right), \\
& z_{W}\left(x_{1}, x_{3}\right)=z_{W}\left(x_{1}, \overline{x_{2}}, x_{3}, \overline{x_{4}}\right), \\
& z_{W}\left(x_{1}, x_{4}\right)=z_{W}\left(x_{1}, \overline{x_{2}}, \overline{x_{3}}, x_{4}\right),
\end{aligned}
$$

$$
\begin{aligned}
& z_{W}\left(x_{2}, x_{3}\right)=z_{W}\left(\overline{x_{1}}, x_{2}, x_{3}, \overline{x_{4}}\right), \\
& z_{W}\left(x_{2}, x_{4}\right)=z_{W}\left(\overline{x_{1}}, x_{2}, \overline{x_{3}}, x_{4}\right), \\
& z_{W}\left(x_{3}, x_{4}\right)=z_{W}\left(\overline{x_{1}}, \overline{x_{2}}, x_{3}, x_{4}\right),
\end{aligned}
$$

where $\bar{x}_{i}$ - the average values of factors $x_{i}(i=1,2,3,4)$.

A schematic representation of the model of such decomposition has been shown in Fig. 4.

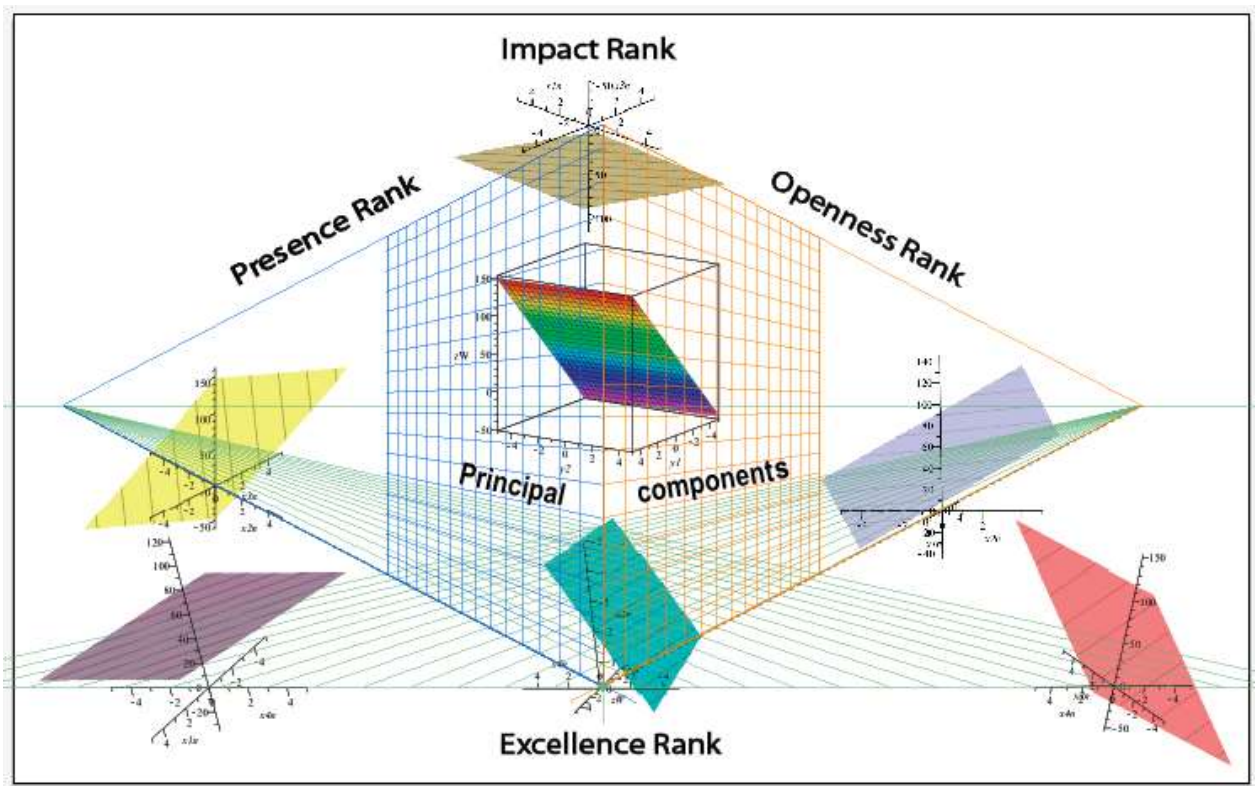

Figure 4. Schematic representation of quantitative and qualitative dependences of the ranking of the top 100 HEIs on Webometrics indicators and principal components (January 2020)

(Calculated by the authors)

It should be noted that graphs in Fig. 1 graphs have been built in the mathematical editor Maple 18, and therefore illustrate not only the qualitative but also the quantitative nature of the dependence of the ranking of the top 100 world universities on Webometric indicators and their principal components according to data in January 2020.
Assessment of the position of Ukrainian HEIs in the Webometric rating

Let's analyze the position of Ukrainian HEIs in the Webometric rating by the algorithm developed in p. 3, 4. The initial data of the analysis are the statistical set of ratings of the 100 best Ukrainian universities and the corresponding indicators of Web-indicators in January 2020, a fragment of which is shown in Fig. 5.

Copyright (C) 2021 Author(s), published by Vytautas Magnus University. This is an open access article distributed under the terms of the Creative Commons Attribution Non-Commercial 4.0 (CC BY-NC 4.0) license, which permits unrestricted use, distribution, and reproduction in any medium provided the original author and source are credited. The material cannot be used for commercial purposes. 


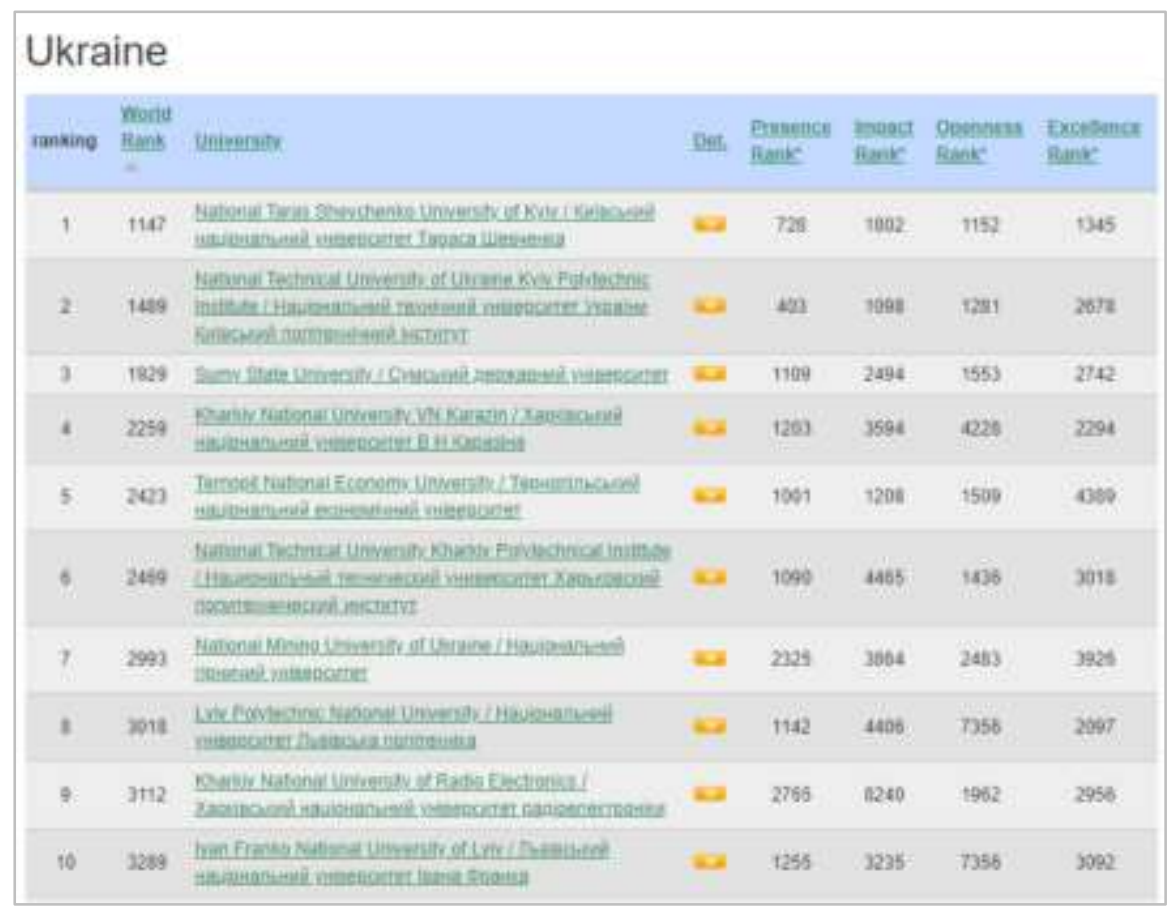

Figure 5. Ukrainian HEIs in the Webometric rating of world universities according to data in January 2020 (Webometrics Ranking of World Universities, 2020)

The above-mentioned notations for factor variables (Webometrics indicators with their weighting factors) will be left unchanged: $x_{i}(i=1,2,3,4)$; effective variable - Rating of universities of Ukraine / Ukraine Rank will be marked $z_{U}$.

Here are the general conclusions based on the results of the analysis of statistical calculations.

\section{Calculation for factor variables of the correlation matrix}

According to the results of calculations there is multicollinearity in the array of factor features: in particular, there are pairs of factor variables: $x_{1}$ and $x_{2} ; x_{1}$ and $x_{4} ; x_{2}$ and $x_{4}$.

And this means that for further statistical analysis it is advisable to use the method of principal components analysis.

\section{Identification of the principal components of factor features}

The identification of the principal components for the selected sample of the top 100 Ukrainian universities according to the data in January 2020 conducted using the Principal Components Analysis tool (Kvitka, Starushenko, 2021).

In this case, there are two eigenvalues that exceed 1: $\lambda_{1}=1,57824$ and $\lambda_{2}=1,10405$; and therefore, there are two main components that together explain $67,057 \%$ of the variability of factor characteristics. According to the calculations given in the Table of Component Weights for a sample set of Web-indicators of the top 100 Ukrainian universities according to the data in January 2020, the equations of the principal components $y_{I U}, y_{2 U}$ have been recorded as:

$y_{I U}=0,626948 x_{1}^{*}+O, 506399 x_{2}^{*}+O, 0997396 x_{3}^{*}+O, 583565 x_{4}^{*}$;

$y_{2 U}=0,20418 x_{1}^{*}-0,451499 x_{2}^{*}+0,868263 x_{3}^{*}+0,0240386 x_{4}^{*}$,

where $x_{i}^{*}(i=1,2,3,4)$ - standardized values of $x_{i}$ variables, determined by relation (3.3). 


\title{
S sciendo
}

\author{
Management Theory and Studies for Rural Business and Infrastructure Development \\ eISSN 2345-0355. 2021. Vol. 43. No. 2: 177-194 \\ Article DOI: https://doi.org/10.15544/mts.2021.15
}

\section{Calculation of factor loads and identification of principal components}

The calculation of factor loads has been carried out for a sample of Web-indicators of the top 100 Ukrainian universities according to the data in January 2020 (table $5.1)$.

Table 2. Calculation of factor loads for the sample Web-indicators of the top 100 Ukrainian universities according to data in January 2020

(Calculated by the authors)

Factor Loading Matrix After Varimax
Rotation
\begin{tabular}{|l|l|l|}
\hline & Factor & Factor \\
\hline & 1 & 2 \\
\hline $\begin{array}{l}\text { Presence Rank } \\
\text { U_Weight 5\% }\end{array}$ & 0,788186 & 0,212458 \\
\hline $\begin{array}{l}\text { Impact Rank } \\
\text { U_Weight 50\% }\end{array}$ & 0,634922 & $-0,476087$ \\
\hline $\begin{array}{l}\text { Openness Rank } \\
\text { U_Weight 10\% }\end{array}$ & 0,127711 & 0,911984 \\
\hline $\begin{array}{l}\text { Excellence Rank } \\
\text { U_Weight 35\% }\end{array}$ & 0,733184 & 0,0233211 \\
\hline
\end{tabular}

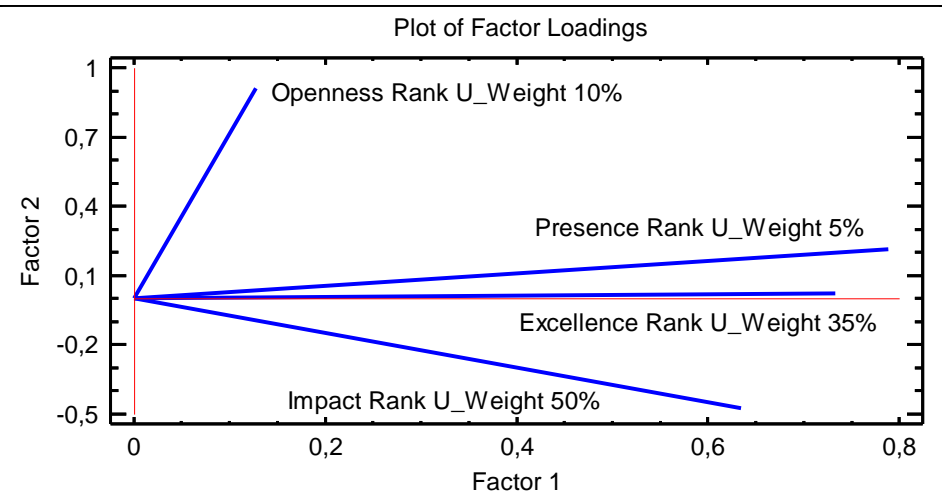

Fig. 5.2. Graph of factor loads after the rotation procedure

The analytical equations for assessing the factor loads after rotation $l_{1}^{\prime}, l_{2}^{\prime}$ have the form:

$$
l_{1}^{\prime}=0,788186 x_{1}^{*}+0,634922 x_{2}^{*}+0,127711 x_{3}^{*}+0,733184 x_{4}^{*} ;
$$$$
l_{2}^{\prime}=0,212458 x_{1}^{*}-0,476087 x_{2}^{*}+0,911984 x_{3}^{*}+0,0233211 x_{4}^{*} \text {, }
$$

where $x_{i}^{*}(i=1,2,3,4)$ is determined by formula (3.3).

The conclusions based on the results of the calculation of principal components and factor loads for the sample set of Webometrics indicators of top-100 Ukrainian universities according to the data in January 2020 are as follows:

1) The first principal component $y_{I U}$ is connected to the following Webometric indicators (grounding on their weight significance in the Webometrics rating): $x_{1}$ : Presence; $x_{4}$ : Excellence; $x_{3}$ : Impact and can be identified as "Volume of Internet content, including external networks related to the University's Web pages, and quality of research papers". The contribution of this component to the total variance of the set of factor features is $39,456 \%$.

2) The second principal component $y_{2 U}$ contributes slightly less to the total variance $(27,601 \%)$ and is related directly to the Web indicator $x_{3}$ : Openness, i.e. it is defined as "Number of citations of the most prominent authors".

Statistical analysis of the influence of Webometric indicators on the generalized indicator of the rating of Ukrainian HEIs

The impact of Web-indicators on the generalized rating of Ukrainian universities according to the data in January 2020 will be assessed on the basis of analysis of two-factor

Copyright (C) 2021 Author(s), published by Vytautas Magnus University. This is an open access article distributed under the terms of the Creative Commons Attribution Non-Commercial 4.0 (CC BY-NC 4.0) license, which permits unrestricted use, distribution, and reproduction in any medium provided the original author and source are credited. The material cannot be used for commercial purposes. 
regression model of dependence of the performance trait $z_{U}$ - Rating of Ukrainian universities / Ukraine Rank from $y_{I U}, y_{2 U}$, principal components of (5.1), (5.2), (3.3) factor signs under consideration.

According to the estimation data [11], the required regression equation has been written in the form:

$$
1+\frac{\left(z_{U}\left(y_{I U}, y_{2 U}\right)\right)^{0,471796}-1}{0,471796 \cdot 5490,84^{-0,528204}}=11636,9+1405,45 y_{I U}+259,427 y_{2 U}
$$

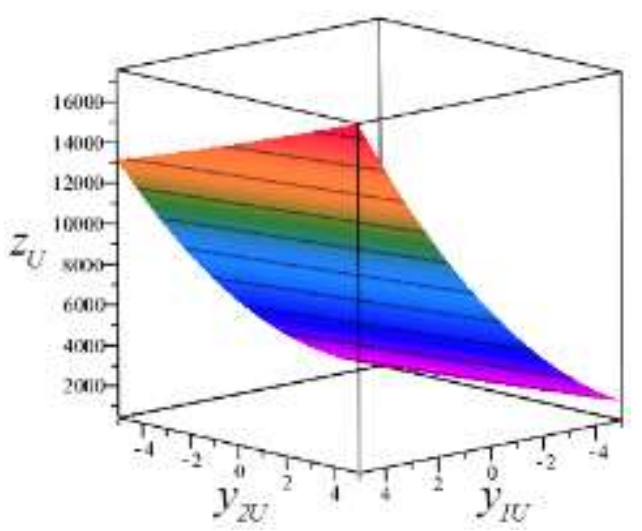

Figure 6. Dependence of the Rating of Ukrainian universities on the principal components

(Source: calculated by the authors)

Analysis of equation (5.3), made by the Analysis Options function of STATGRAPHICS, showed that it is the best one in comparison with alternative models by the coefficient of determination ( $R$-squared) $R^{2}=76,2972$, i.e. the constructed model explains $76,2972 \%$ of the variation of the resultant factor.

In fig. 7 graphically illustrates the dependences:

$$
\text { - } z_{U I}=f\left(y_{I U}, \overline{y_{2 U}}\right) \text { - dependence of the }
$$

Rating of Ukrainian universities on the first principal component $y_{I U}$ with the average value $\overline{y_{2 U}}$ of the second principal component $y_{2 U}$ :

$$
\begin{gathered}
z_{U 1}\left(y_{I U}\right)=\left(59,1115+7,01904 y_{I U}\right)^{2,11956} ; \\
\text { - } z_{U 2}=f\left(\overline{y_{U U}}, y_{2 U}\right) \text { - respectively, the }
\end{gathered}
$$

dependence of the Rating of Ukrainian universities on the second principal component or by converting it to an explicit expression:

$$
z_{U}\left(y_{I U}, y_{2 U}\right)=\left(59,1115+7,01904 y_{I U}+1,29562 y_{2 U}\right)^{2,11956}
$$

Regression dependence (5.3) of the Rating of Ukrainian universities (Ukraine Rank) $z_{U}$ on the principal components $y_{I U}$, $y_{2 U}$, has been illustrated graphically in Fig. 6, and was made in the mathematical editor Maple 18.

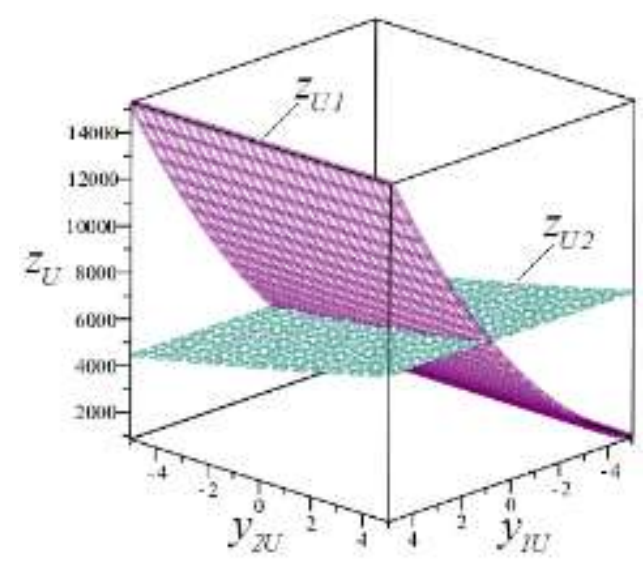

Figure 7. Dependence of the Rating of Ukrainian universities on each of the principal components with the average value of the other ones

$y_{2 U}$ with the average value $\overline{y_{I U}}$ of the first $y_{I U}:$

$$
z_{U 2}\left(y_{2 U}\right)=\left(59,1115+1,29562 y_{2 U}\right)^{2,11956} \text {. }
$$

The regression equation (5.3) can be written taking into account the relations (5.1), (5.2), (3.3) and summary statistics. It has been presented as a function of initial variables $x_{i}(i=1,2,3,4)$.

In this case, after some transformations we get:

$z_{U}\left(x_{1}, x_{2}, x_{3}, x_{4}\right)=\left(24,3669+0,0272951 x_{1}+0,00159831 x_{2}+0,00808989 x_{3}+0,0101478 x_{4}\right)^{2,11956}$

The dependence of the Rating of Ukrainian universities calculated by formula (5.4), has been graphically illustrated by graphs (Fig. 8, Fig. 9) accordingly to the variables $x_{1}, x_{2}$ and $x_{3}, x_{4}$ and the average values of factors $x_{3}, x_{4}$ and $x_{1}, x_{2}$, namely: 


\title{
S sciendo
}

\author{
Management Theory and Studies for Rural Business and Infrastructure Development \\ eISSN 2345-0355. 2021. Vol. 43. No. 2: 177-194 \\ Article DOI: https://doi.org/10.15544/mts.2021.15
}

$$
\begin{gathered}
z_{U 12}\left(x_{1}, x_{2}\right)=f\left(x_{1}, x_{2}, \overline{x_{3}}, \overline{x_{4}}\right): \\
z_{U 12}\left(x_{1}, x_{2}\right)=\left(46,5041+0,0272951 x_{1}+0,00159831 x_{2}\right)^{2,11956} ; \\
z_{U 34}\left(x_{3}, x_{4}\right)=f\left(\overline{x_{1}}, \overline{x_{2}}, x_{3}, x_{4}\right): \\
z_{U 34}\left(x_{3}, x_{4}\right)=\left(36,9543+0,00808989 x_{3}+0,0101478 x_{4}\right)^{2,11956} .
\end{gathered}
$$

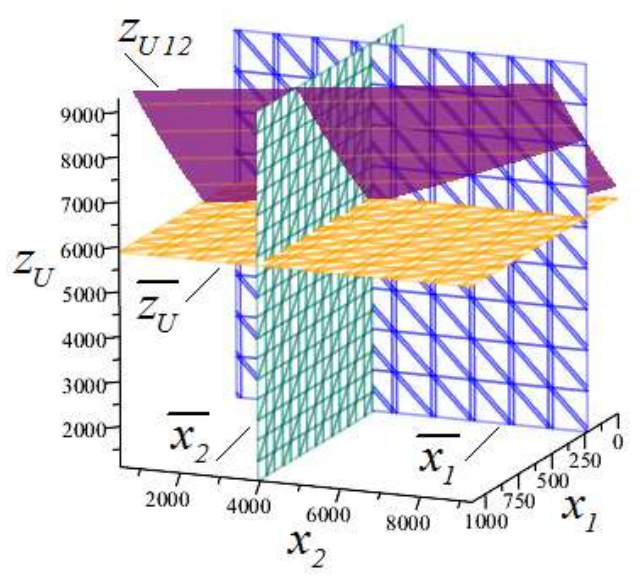

Figure 8. Dependence of Ukrainian HEIs

Rating on factors $x_{1}$ : Presence and $x_{2}$ : Impact taking into account their weight significance

Comparative analysis of the rating of leading Ukrainian and world universities in the Webometrics system

In the context of global trends, the level of professional training of a HEI's graduate and, as a consequence, his competitiveness in the labor market is an integral indicator. It also counts the prestige of the educational institution in which a person was educated and the place, which the institution occupies in the world and national ratings. With the entry of Ukraine into the world educational and scientific space, the problems faced by domestic HEIs have intensified. One of the problems is low rating positions of Ukrainian HEIs in the world, even of the leading ones. That is why it is necessary to analyze
For comparison, the same graphs show the planes of the average values of the corresponding variables:

$$
\begin{gathered}
\cdot \quad \text { in fig. } 5.4: \quad x_{1}=\overline{x_{1}}=230,804 ; \\
x_{2}=\overline{x_{2}}=3946,41 ; \quad z_{U}=\overline{z_{U}}=5889,24 ; \\
\bullet \quad \text { in fig. } 5.5: \quad x_{3}=\overline{x_{3}}=448,747 ; \\
x_{4}=\overline{x_{4}}=1825,71 ; \quad z_{U}=\overline{z_{U}}=5889,24 .
\end{gathered}
$$

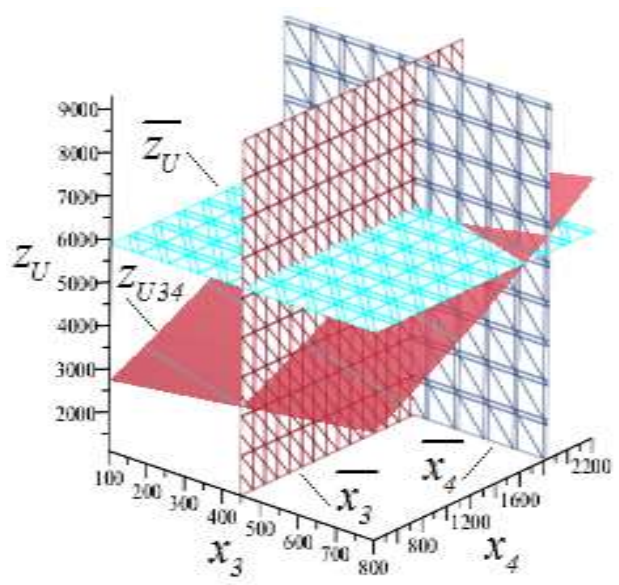

Figure 9. Dependence of Ukrainian HEIs on factors $x_{3}$ : Openness and $x_{4}$ : Excellence taking into account their weight significance

objectively and to identify the factors that cause the current situation, and to develop the grounded suggestions for its systematic improvement.

\section{Comparison of the rating of Ukrainian} HEIs and the best universities in the world in terms of the principal components

According to the results of the statistical analysis made in p.3 and p.5 the principal components and factors that form them have been shown for the Ukrainian HEIs and the world ones. It has been found that the principal components that cause the most significant impact on the overall Webometric rating differ significantly for the best world and Ukrainian universities (Fig. 10). Thus, the most important

Copyright (C) 2021 Author(s), published by Vytautas Magnus University. This is an open access article distributed under the terms of the Creative Commons Attribution Non-Commercial 4.0 (CC BY-NC 4.0) license, which permits unrestricted use, distribution, and reproduction in any medium provided the original author and source are credited. The material cannot be used for commercial purposes. 
for the world's leading HEIs are Webindicators: $x_{2}$-Impact; $x_{3}$-Openness.

And these factors determine the high level of the overall ranking of world universities as they have, on average, better rating scores than factors $x_{1}$ and $x_{4}$ (summary statistics on Web-indicators of the world's leading and leading Ukrainian HEIs according to the data in January 2020 (excluding weights) presented in Kvitka, Starushenko, 2021).

At the same time, the first principal component for the leading Ukrainian HEIs is loaded (Table 3) by Web-indicators (in descending order of weight): $x_{1}$ - Presence; $x_{4}$ - Excellence; $x_{2}$ - Impact, the average levels of which are worse than the average value of the second principal component.

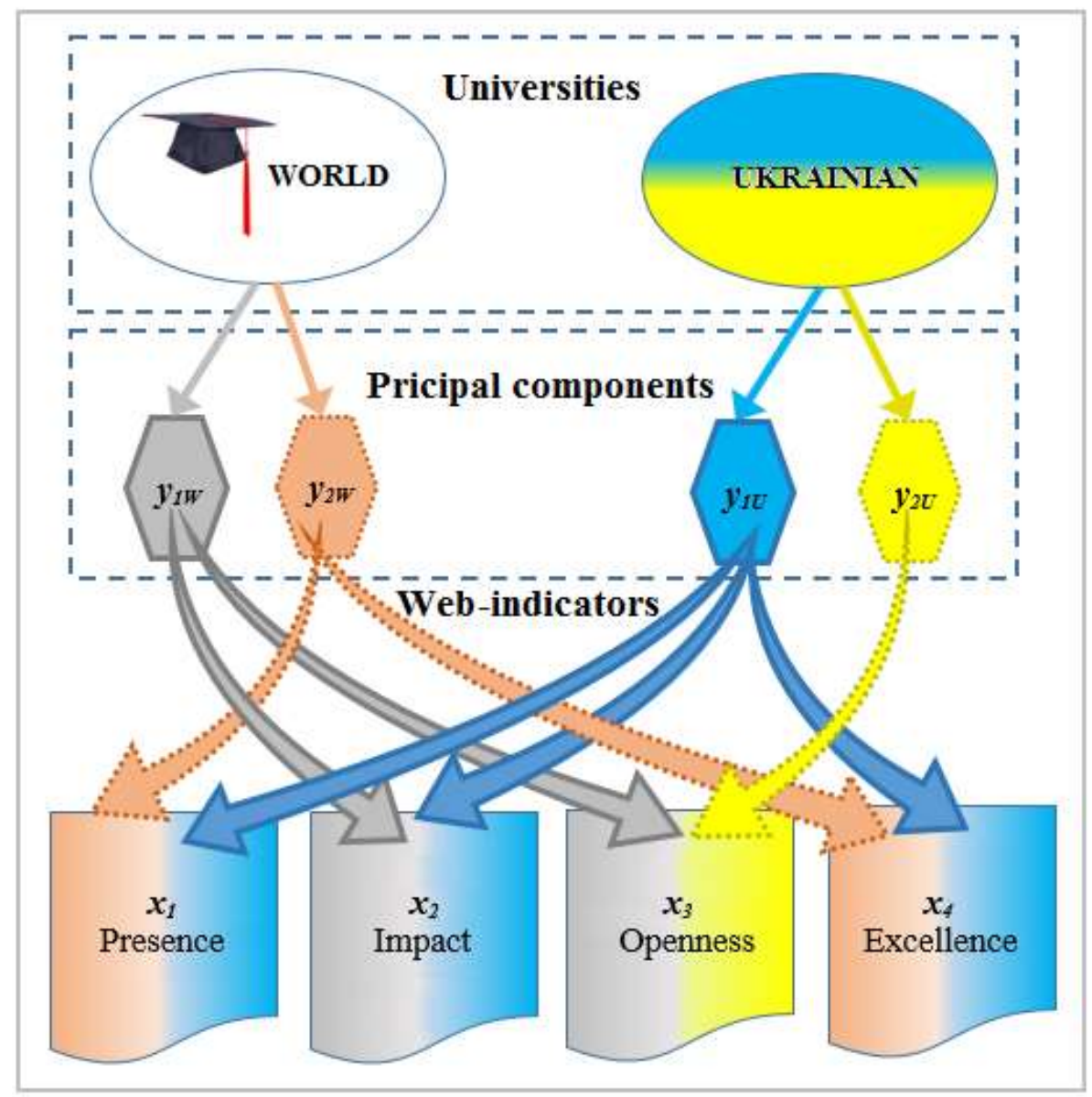

Figure 10. The scheme of principal components' loadings distribution by Web-indicators for the best world and Ukrainian HEIs according to data in January 2020

(Source: calculated by the authors)

This means that in order to improve fundamentally the representation of Ukrainian HEIs in the Webometric space, they need, first of all, to take measures aimed at the comprehensive improvement of all the abovementioned indicators, namely, to increase the amount of Internet content, including external networks related to Web- pages of the HEI, and to high the quality of scientific works.
Assessment of the rating of the leading world and Ukrainian HEIs according to correlation coefficients

The correlation coefficients between each pair of variables for the leading HEIs of the world and Ukraine (Tyutyunnyk, Gritselyak, 2013) indicate the existence of statistically significant non-zero correlations in both samples at a confidence level of 95,0\% ( $P$-value is less than 0,05$)$, namely: 


\title{
Sciendo
}

\author{
Management Theory and Studies for Rural Business and Infrastructure Development \\ eISSN 2345-0355. 2021. Vol. 43. No. 2: 177-194 \\ Article DOI: https://doi.org/10.15544/mts.2021.15
}

- for world HEIs: between a pair of variables $z_{W}$ : World rating (Rank W) and the first principal component $y_{I W}$ (PCOMP_1 $\mathrm{W})$;

- similarly for Ukrainian HEIs: between a pair of variables $z_{U}$ : Rating of Ukrainian HEIs (Rank U) and the first principal component $y_{I U}$ (PCOMP_1 U).

This confirms the conclusion that the first principal component has a significant impact on the overall ranking of both global and Ukrainian HEIs.

In addition, the presence of the determining influence of the first principal component on the overall rating of world and Ukrainian HEIs is proven also by the calculations provided by partial correlation coefficients, shown in in table. 3. They estimate, in particular, the "net" influence of each factor (excluding the influence of another factor) on the performance variable.

Table 3. Partial correlation coefficients of Web-indicators of the world's top 100 and the top 100 Ukrainian universities according to data in January 2020

(Source: calculated by the authors)

Partial Correlations W
\begin{tabular}{|l|l|l|l|}
\hline & Rank W & PCOMP_1 W & PCOMP_2 W \\
\hline Rank W & & 0,9492 & 0,0471 \\
\hline & & $(100)$ & $(100)$ \\
\hline & & 0,0000 & 0,6431 \\
\hline PCOMP_1 W & 0,9492 & & $-0,0447$ \\
\hline & $(100)$ & & $(100)$ \\
\hline & 0,0000 & & 0,6601 \\
\hline PCOMP_2 W & 0,0471 & $-0,0447$ & \\
\hline & $(100)$ & $(100)$ & \\
\hline & 0,6431 & 0,6601 & \\
\hline
\end{tabular}

However, the data presented in this table indicate also significant differences in identifying the "net" influence of factors on the performance factor for global and Ukrainian HEIs:

- for global HEIs there is no statistically significant non-zero correlation at a confidence level of $95,0 \%$ between a pair of variable $z_{W} \mathrm{~s}$ : World rating (Rank $\mathrm{W}$ ) and the second principal component $y_{2 W}$ (PCOMP_2 W), as in this case $P=0,6431>0,05$;

- at the same time, for a pair of variables for Ukrainian HEIs $z_{U}$ : It is $P=0,0333<0,05$ for the Ukrainian HEIs rank (Rank $\mathrm{U}$ ) and the second principal component $y_{2 U}$ (PCOMP_2 $\mathrm{U})$, which indicates a statistically significant

Partial Correlations U
\begin{tabular}{|l|l|l|l|}
\hline & Rank U & PCOMP_1 U & PCOMP_2U \\
\hline Rank U & & 0,8468 & 0,2141 \\
\hline & & $(100)$ & $(100)$ \\
\hline & & 0,0000 & 0,0333 \\
\hline PCOMP_1 U & 0,8468 & & $-0,1813$ \\
\hline & $(100)$ & & $(100)$ \\
\hline & 0,0000 & & 0,0724 \\
\hline PCOMP_2 U & 0,2141 & $-0,1813$ & \\
\hline & $(100)$ & $(100)$ & \\
\hline & 0,0333 & 0,0724 & \\
\hline
\end{tabular}

non-zero correlation between these factors at 95,0\% confidence level.

Thus, the Webometric Rating of Ukrainian HEIs is also influenced significantly by the second principal component $y_{2 U}$ : The number of citations of the most prominent authors. The values of this factor are on average better than other Web-indicators according to the data in January 2020 (Table 6.1 ), but the results for this factor also should be improved to lift the rating of Ukrainian HEIs in the Webometrics system.

\section{Conclusions}

Summarizing the results of the statistical analysis, let's draw general conclusions and

Copyright (C) 2021 Author(s), published by Vytautas Magnus University. This is an open access article distributed under the terms of the Creative Commons Attribution Non-Commercial 4.0 (CC BY-NC 4.0) license, which permits unrestricted use, distribution, and reproduction in any medium provided the original author and source are credited. The material cannot be used for commercial purposes. 
recommendations for each of the Webometrics indicators. These recommendations should be taken into account when developing and improving the Web-policy for Ukrainian HEIs.

1) To lift the position by the Presence indicator, it is necessary:

- to increase the number of pages of the HEI's website with various content related to educational work, methodological support of the educational process, scientific activity and international cooperation of teachers, staff and students of the institution;

- to post systematically abstracts of reports from scientific and practical conferences, presentations at seminars, materials of round tables and other research events held in the institution: Webometrics pays considerable attention to such types of scientific work;

- to develop and implement e-learning courses;

- to develop English-language educational programs with their detailed presentation on the HEI's website;

- to expand and develop multilingual versions of the university's website.

2) In terms of Impact rating lifting, it is advisable:

- to increase the presence of HEI in social networks;

- to implement actively academic mobility programs, such as internships, advanced training, professional retraining, business trips to exchange experiences, to develop joint research projects and programs or to participate in international scientific events;

- to expand the cooperation and interaction with foreign colleagues, universities and research institutions;

- to invite to study foreign students in the framework of exchange programs;

- to participate in international research projects;

- to include links to the university website in scientific publications.

3) To lift the indicators on Openness criterion, the attention should be paid to:

- provision of the open access to all scientific developments of HEIs: research projects, scientific journals and materials of conferences held in the institution; materials of dissertations defended in specialized scientific councils of HEIs;

- intensification of scientific interaction with the academic environment - domestic academic institutes, leading foreign institutions, the world's scientific elite in order to conduct joint research and publish their results;

- researches of scientific problems, priority on the relevant topics in foreign scientific circles;

- encouraging HEI's scientists to publish their scientific papers in English-language journals and periodicals;

- implementation of a system of grants for priority basic and applied researches;

- constant and prompt updating of the scientific database of HEI's site.

4) Regarding the lifting of the Excellence indicator, it makes sense to take the following measures:

- to encourage HEI's scientists to publish the results of their researches in domestic and foreign publications, which are referenced in Scopus and Web of Science scientometric databases;

- to strengthen the requirements for the quality of scientific papers published in domestic printed and online papers - journals, collections of scientific papers, collections of abstracts at conferences, etc;

- for editorial boards to improve the international rating of Ukrainian scientific journals and periodicals, in particular, by including them into the scientometric databases Scopus and / or Web of Science (for unreferred journals) and by raising the quartile of the journal (for publications referenced in these databases);

- similar to leading European scientific journals, to introduce a system of "black reviewers" everywhere in Ukrainian scientific journals, the reviewing of scientific articles by independent experts, anonymous to the authors;

- to direct efforts of domestic scientists to the improvement of the quality of research papers in order to increase the competitiveness of their publications in the world scientific space. 


\title{
Sciendo
}

\author{
Management Theory and Studies for Rural Business and Infrastructure Development \\ eISSN 2345-0355. 2021. Vol. 43. No. 2: 177-194 \\ Article DOI: https://doi.org/10.15544/mts.2021.15
}

\section{References}

Almind, T. C., \& Ingwersen, P. (1997). Informetric Analyses on the World Wide Web: Methodological Approaches to "Webometrics". Journal of Documentation, 53 (4), 404-426.

Bantash, A., Koval, V., Bashynska, M., \& Kozlovtseva, V. (2020). Balanced territorial economic development in the conditions of providing stability of human resources management. Economics. Ecology. Socium, 4(3), 58-66.

Cybermetrics Lab (2020). Retrieved from http://cchs.csic.es/es/research-lab/laboratorio-cibermetria.

Erina, A. M. (2001). Statistical modeling and forecasting: manual. Kyiv: KNEU [in Ukrainian].

Euroosvita (2019). A new Webometrics rating was published. Edition 2019.1.0. Retrieved from http://www.euroosvita.net/index.php/?category=1\&id=5931 [in Ukrainian].

Hazelkorn, E. (2015). Rankings and the Reshaping of Higher Education: The Battle for World-Class Excellence. 2nd ed. London: Palgrave Macmillan.

Hedclub (2019). Webometrics Ranking of World Universities: January 2019. Retrieved from https://hedclub.com/ru/library/webometrics_ranking_of_world_universities_january_2019.

Ingwersen, P. (2006). Webometrics - Ten Years of Expansion. Retrieved from http://eprints.rclis.org/7554/1/ingwersen.pdf

Johnson, R. A., \& Wichern, D. W. (2007). Applied Multivariate Statistical Analysis. 6th ed. Pearson Prentice Hall, New Jersey.

Kodrin, L. (2020). Perceived quality management of educational services from the perspective of parents as stakeholders. Economics. Ecology. Socium, 4(1), 41-52.

Koval, V., Polyezhayev, Y., \& Bezkhlibna, A. (2018). Communicative competences in enhancing of regional competitiveness in the labour market. Baltic Journal of Economic Studies, 4(5), 105-113. doi:10.30525/2256-0742/20184-5-105-113

Krush, P. V., Zaborovets, O. P. \& Zaborovets, M. O. (2010). Analysis of theoretical and methodological approaches to assessment of the effectiveness and efficiency of innovation activities of Ukrainian scientific institutions. Modern problems of economics and entrepreneurship, 5 (part I), 65-71.

Kučaidze, N., \& Jurgelevičius, A. (2020). The impact of high fee-low-subsidy and low fee-high-subsidy higher education funding models on higher education access in European Union countries. Economics. Ecology. Socium, 4(4), 37-46.

Kunosić, S., Čeke, D., \& Zerem, E. (2019). Advantages and Disadvantages of the Webometrics Ranking System. In Scientometrics Recent Advances. IntechOpen. https://doi.org/10.5772/intechopen.87207

Kvitka, S. \& Starushenko, G. (2021). Modern innovative factors of increasing the international competitiveness of higher educational institutions of Ukraine in the context of the digital transformation of society. Public Administration Aspects. 9(1), 5-21 [in Ukrainian]

Kvitka, S., Starushenko, G., Koval, V., Deforzh, H., \& Prokopenko, O. (2019). Marketing of Ukrainian higher educational institutions representation based on modeling of Webometrics Ranking. Marketing and Management of Innovations, 3, 60-72.

Ministry of Education and Science of Ukraine (2018). Some issues of the state certification of scientific institutions. No. 1008. (2018). Retrieved from https://zakon.rada.gov.ua/laws/show/z1504- 18 [in Ukrainian].

QS Quacquarelli Symonds (2020). QS World University \& Business School Rankings. Retrieved from https://www.qs.com/rankings/.

Rauhvargers, A. (2013). Global university rankings and their impact. Report II. Brussels: European University Association asbl.

Salmi, J., \& Saroyan, A. (2007). League Tables as Policy Instruments: Uses and Misuses. Higher Education Management and Policy, 19 (2), 31-68.

ShanghaiRanking Consultancy (2020). About Academic Ranking of World Universities. Retrieved from http://www.shanghairanking.com/aboutarwu.html.

Spanish National Research Council (2020). Retrieved from https://rio.jrc.ec.europa.eu/en/organisations/spanishnational-research-council-csic.

Copyright (C) 2021 Author(s), published by Vytautas Magnus University. This is an open access article distributed under the terms of the Creative Commons Attribution Non-Commercial 4.0 (CC BY-NC 4.0) license, which permits unrestricted use, distribution, and reproduction in any medium provided the original author and source are credited. The material cannot be used for commercial purposes. 

rankings

Times Higher Education (2020). Retrieved from https://www.timeshighereducation.com/world-university-

Tyutyunnyk, A.V., \& Gritselyak, B. I. (2013). Basic criteria and indicators of webometric rating of universities around the world. Information technology and teaching tools, 38 (6), 234-244 [in Ukrainian].

Webometrics Ranking of World Universities (2020). Ranking Web of Universities. Retrieved from http://www.webometrics.info.

Yankovyi, O., Koval, V., Trokhymets, O., Karpenko, M., Matskevich, Y. (2020). Economic assessment of investment on the basis of production functions. Turismo: Estudos \&Práticas, 2. 